\title{
PERIOPERATIVE ANAESTHESIA MANAGEMENT OF A PATIENT WITH CUSHING'S SYNDROME DUE TO ADRENOCORTICAL CARCINOMA: A CASE REPORT
}

\author{
Mukund Parchandekar ${ }^{1}$, Poornima Sonkamble², Sneha Sikchi ${ }^{3}$, Kirankumar Nagure ${ }^{4}$
}

\section{HOW TO CITE THIS ARTICLE:}

Mukund Parchandekar, Poornima Sonkamble, Sneha Sikchi, Kirankumar Nagure. "Perioperative Anaesthesia Management of a Patient with Cushing's Syndrome due to Adrenocortical Carcinoma: A case report". Journal of Evolution of Medical and Dental Sciences 2014; Vol. 3, Issue 47, September 25; Page: 11477-11482,

DOI: $10.14260 /$ jemds/2014/3503

\begin{abstract}
Adrenocortical carcinoma, a rare malignancy is a rare cause of Cushing's syndrome. Open adrenalectomy, a preferred modality for its treatment has inherent problems of difficult surgical access, bleeding, massive blood transfusion, coagulation defect, pulmonary embolism, large fluid shifts, cardiovascular collapse and postoperative complications. Cushing syndrome also poses challenge to anaesthesiologist in perioperative period, due to presence of hyper-cortisolism, volume overload, hypertension, hyperglycemia, hypokalaemia, difficult airway and difficult ventilation. We report a case of Cushing's syndrome due to adrenocortical carcinoma in 50 year old female, who was diagnosed by her clinical presentation, blood investigations and radiological reports. During open adrenalectomy, excessive bleeding had occurred as tumour had invaded inferior vena cava. This was successfully managed with crystalloids, colloids, whole blood, fresh frozen plasma, platelet transfusion and vasopressor support. Postoperative management in PACU included mechanical ventilation, anti-hypertensive and steroids. Inferior vena cava invasion by tumour was not there in earlier CT scan images. Inadvertent inferior vena cava invasion by tumour adds not only to surgical difficulty but also to the problems of anaesthesiologist in managing Cushing syndrome. For successful outcome one has to be prepared for such an un-anticipated problem.
\end{abstract}

KEYWORDS: Cushing's syndrome, adrenocortical carcinoma, perioperative management

INTRODUCTION: Clinical features of Cushing's syndrome are well known to physicians and endocrinologists but these may not be equally understood by anaesthesiologists and surgeons.[1] Causes of this rare endocrine disorder include adrenal hyperplasia secondary to ACTH overproduction, adrenal neoplasia, and prolonged use of exogenous glucocorticoids. Approximately $20-25 \%$ of patients with Cushing's syndrome have an adrenal neoplasm, usually unilateral, and about half of these are malignant.[2]

Adrenocortical carcinoma is an uncommon cause of Cushing's syndrome, which tends to metastasize to inferior vena cava posing a challenge to anaesthesiologist and surgeon during its surgical removal.[3] Here, we are reporting perioperative anaesthesia management of Cushing's syndrome due to adrenocortical carcinoma having inadvertent inferior vena cava invasion.

CASE REPORT: A 50 year female, presented with generalized weakness, oedema feet, facial puffiness (moon face), abdominal striae, ecchymotic patches, hirsuitism, hypertension (200/120 mmHg), and diabetes mellitus of 6 months duration. She was receiving tablet telmasartan, hydrochlorthiazide, aspirin, metformin for her blood pressure (BP) and blood sugar control. Laboratory investigations 
revealed low platelets $\left(46000 / \mathrm{mm}^{3}\right)$, high blood sugar $(170 \mathrm{mg} / \mathrm{dl})$, high serum cortisol $(45.06$ $\mu \mathrm{g} / \mathrm{dl})$, and low Serum $\mathrm{K}^{+}(2.4 \mathrm{mEq} / \mathrm{L})$.

Electrocardiography and echocardiography diagnosed left ventricular hypertrophy. USG abdomen and CECT abdomen showed large right adrenal mass causing displacement of inferior vena cava anteriorly. NCCT brain revealed senile cortical atrophic changes. Subsequently, she was diagnosed to be a case of Cushing's syndrome with malignant right adrenal mass and was posted for right open adrenalectomy.

Preoperative preparation included platelet transfusions, potassium supplement shifting patient on insulin. Sorbitrate was continued and BP was controlled with amlodipin and metoprolol. Ketoconazole (inhibitor of steroidogenesis) was given orally in the dose of $200 \mathrm{mg}$ three times daily for 3 days.

The patient having height $156 \mathrm{~cm}$ and weight $53 \mathrm{~kg}$ was fully conscious and oriented preoperatively. Her vitals were stable, having pulse rate $96 / \mathrm{min}$, respiratory rate $18 / \mathrm{min}, \mathrm{SPO}_{2} 98 \%$ on air, blood pressure $130 / 90 \mathrm{mmHg}$, temperature $37^{\circ} \mathrm{C}$, and morning blood sugar level $140 \mathrm{mg} \%$. Systemic examination did not reveal any abnormality. We planned general anaesthesia with epidural analgesia for her. Monitors like ECG, pulse oximeter, $\mathrm{ETCO}_{2}$, NIBP, temperature were applied.

Patient was catheterized with Foleys catheter no. 14 and intravenous line was secured with 18G intracath. For central venous pressure and invasive blood pressure monitoring, right IJV line and left radial arterial line established. Insulin (10 units) + Kesol (20mEq/L) drip in $500 \mathrm{ml}$ normal saline was started at the rate of $50 \mathrm{ml} / \mathrm{hr}$. Patient was pre medicated with midazolam and fentanyl.

After pre oxygenation, patient was induced with thiopentone and intubated under effect of suxamethonium, Anaesthesia was maintained with oxygen, nitrous oxide, sevoflurane and intermittent atracurium. Epidural analgesia was provided with $0.125 \%$ bupivacaine intermittently.

Abdomen was opened via thoracolumbar approach. After starting the operative procedure patient's BP shoot up to 190/110 mmHg which was controlled with IV metoprolol $1 \mathrm{mg}$ in incremental doses up to $4 \mathrm{mg}$ and IV nitroglycerine drip at the rate of $0.5-1 \mu \mathrm{g} / \mathrm{kg} / \mathrm{min}$. At the start of tumour resection, hydrocortisone $100 \mathrm{mg}$ IV bolus given and infusion was started at the rate of $100 \mathrm{mg}$ per 24 hours.At the time of tumour dissection, IVC invasion by tumour mass, and a large adrenal vein and an accessory vein from the tumour draining into IVC were observed.

Tumour resection and removal of IVC tumour thrombus was achieved by caval clamping alone. During this maneuver, there occurred excessive bleeding measuring about $2500 \mathrm{ml}$. Blood pressure dropped down to $60 / 40 \mathrm{mmHg}$ and pulse rate increased to $150-160 / \mathrm{min}$. NTG drip stopped.

To raise blood pressure, mephenteramine $6 \mathrm{mg}$ IV in incremental doses up to $24 \mathrm{mg}$, dopamine was started at the rate of $4-5 \mu \mathrm{g} / \mathrm{kg} / \mathrm{min}$ along with crystalloids $3000 \mathrm{ml}$, colloids $1000 \mathrm{ml}, 1400 \mathrm{ml}$ blood, $600 \mathrm{ml}$ fresh frozen plasma. Blood pressure came to normal. Intraoperative urine output was $1800 \mathrm{ml}$. Surgery lasted for five and half hours.

At the end of surgery, neuromuscular blockade was reversed with neostigmine. Due to weak respiratory efforts, patient needed mechanical ventilation for 2 days. There after extubation was done and $\mathrm{O}_{2}$ supplementation was provided with face mask.

In PACU raised BP was managed with NTG drip and metoprolol. Remaining blood loss replacement was done in PACU with $1050 \mathrm{ml}$ of fresh blood. Hydrocortisone continued in tapering dose as $100 \mathrm{mg} / 24 \mathrm{hrs}, 75 \mathrm{mg} / 24 \mathrm{hrs}, 50 \mathrm{mg} / 24 \mathrm{hrs}, 25 \mathrm{mg} / 24 \mathrm{hrs}$ and patient shifted on oral prednisolone $10 \mathrm{mgthrice}$ daily. On $8^{\text {th }}$ postoperative day patient was shifted to ward. 
Adrenal tumours are not biopsied prior to surgery, so diagnosis is confirmed on examination of the surgical specimen by a pathologist. In this case, histopathological report of tumour specimen revealed adrenocortical carcinoma.

DISCUSSION: Cushing's syndrome is fairly rare having prevalence of $39.1 /$ million inhabitants and average incidence 2.4 cases/million/year. It is more frequent in females than in males.[4] It is characterized by hypercortisolism and side effects of excessive steroids are hyperglycemia, hypertension, fluid overload, protein catabolism, immune-suppression, increased susceptibility to infection and impaired wound healing. ${ }^{[2]}$

Clinical features of Cushing's syndrome are moon face, oedema, central obesity with buffalo hump, thin skin, purple striae on abdomen and thighs, myopathy, proximal muscle wasting, amenorrhea, hirsuitism, feminization, osteoporosis, hypertension, left ventricular hypertrophy, glucose intolerance- Type II diabetes mellitus and hypokalaemia due to weak mineralocorticoid effect. ${ }^{[5]}$ In our case, clinical presentation was similar to classical features of Cushing's syndrome.

Adrenocortical carcinoma, also called as adrenal cortical carcinoma (ACC) and adrenal cortex cancer, is an aggressive cancer with poor prognosis originating in the cortex of the adrenal gland. It is rare tumour having annual incidence of $0.5 /$ million population shows bimodal age incidence with most patients 40 to 50 years old and higher prevalence in females, most presenting with Cushing's syndrome.[6] ACC can be diagnosed by the endocrine signs of steroid excess, symptoms due to tumour growth or an adrenal incidentaloma.

Hormonal investigations demonstrate in most ACC steroid over secretion, the dominant character being a co-secretion of cortisol and androgens. Imaging by CT scan or MRI shows a large heterogeneous tumour with a low fat content. ${ }^{[7]}$ In our case, brain CT scan revealed senile cortical atrophic without any enlargement of the pituitary fossa which ruled out any pituitary tumour and diagnosis of adrenal tumour was confirmed by CECT abdomen.

$62 \%$ of adrenal tumours are functional and functioning ACC may secrete excess cortisol (30\%), androgens (20\%), estrogens (10\%), aldosterone (10\%), or a combination after $(35 \%) .[6,8]$ ACC more than $6 \mathrm{~cm}$ of size may secrete more than one hormone. ${ }^{[9]} \mathrm{ACC}$ tends to metastasize to the liver, lungs, kidney, renal vein and inferior vena cava. Rarely tumour thrombus may extend through inferior vena cava (IVC) to the right atrium.[3]

In our case, CECT abdomen showed large right adrenal mass of size $12.5 \times 9.3 \times 10.3 \mathrm{~cm}$ causing displacement of IVC anteriorly without IVC invasion. Echocardiography did not show thrombus extension in the right atrium and right ventricular function was normal. During tumour dissection, tumour thrombus invading IVC was noticed. This could be happened due to "time lag" between diagnosis and operation, and aggressiveness of ACC. This time lag was taken by management of Cushing's syndrome and preparation of the patient for the surgery.

The role of laparoscopic adrenalectomy though superior in benign pathology, is controversial in the treatment of patients with ACC. Complete surgical resection is the mainstay of treatment for patients with ACC.[10] Surgical removals of a localized tumor and absent metastatic disease were associated with improved survival.[11]

Surgical removal poses a challenge to both surgeons and anaesthesiologist because of the complications involving surgical access, bleeding, massive blood transfusion, coagulation defect, pulmonary embolism, large fluid shift, and significant perioperative complications.[3] 
IVC involvement a controversial risk for surgical treatment was managed by thrombectomy, partial resection with direct closure or total resection with replacement of the IVC. Venous control was achieved by caval clamping alone, hepatic vascular exclusion and the use of normothermic cardiopulmonary bypass or hypothermic circulatory arrest.[11]

In patients with functional adrenal tumours undergoing adrenalectomy, epidural anaesthesia in addition to general anaesthesia might be an effective and safe method to prevent the fluctuations in hormone levels.[12] To avoid haemodynamic instability, glucocorticoid replacement is advised at the start of tumour resection at a dose equal to full replacement of adrenal output during periods of extreme stress to avoid haemodynamic instability.[2]

If the best results are to be obtained in operative morbidity and mortality, the need for optimal diabetic control and blood pressure control is highlighted by the reviews on surgical management of this tumour.[13] Ketoconazole is an imidazole derivative that inhibits steroidogenesis by acting on P450 enzymes in the adrenals. Ketoconazole is commonly used because of its effectiveness as monotherapy and favorable side-effect profile.[14]

In spite of pre, intra and postoperative management, Cushing's syndrome causes reduced life quality and increased mortality. These patients are care-intensive, despite the best care, the overall prognosis of ACC is poor with a 5 year survival rate below $30 \%$ in most series. ${ }^{[1,4,7]}$ Multidisciplinary team involving endocrinologist, neurosurgeon, general surgeon, or urologist, and anaesthesiologist can assure better management in Cushing's syndrome.

As surgery in Cushing's syndrome is a challenge to the anaesthesiologist, hallmarks of the anaesthesiologist role in treating such patient are the control of perioperative hypertension, hyperglycemia, hypokalaemia and cortisol blood levels.[15]

In conclusion, for this rare malignancy treatment outcome is still unsatisfactory. Paucity of experience in perioperative management of adrenocortical carcinoma requires early diagnosis, treatment protocols and suspicion of un-anticipated problem in perioperative period.

\section{REFERENCES:}

1. Domi R and Sula H. Cushing syndrome and the anaesthesiologist, two case reports. Indian J Endocrinol Metab. 2011 Jul-Sep; 15 (3): 209-213

2. Kulkarni A, Rastogi G, Bhargava A. Anesthetic management of resection of a cortisol secreting tumour: Cushing's syndrome, perioperative steroid replacement. The Internet Journal of Anesthesiology, ISSN: 1092-406X, 2007; 14 (1).

3. Kumar K, Basker S, Jeslin L, Srinivasan C, Reden E. Anesthetic management for removal of adrenocortical carcinoma with thrombus in the inferior vena cava extending to the right atrium. J Anaesthesiol Clin Pharmacol. 2011 Oct-Dec; 27 (4): 571-573.

4. Etxabe J, Vazquez JA. Morbidity and mortality in Cushing's disease: an epidemiological approach. Clin Endocrinol (Oxf). 1994 Apr; 40 (4): 479-84.

5. Davies M, Hardman J. Anaesthesia and adrenocortical disease. Continuing Education in Anaesthesia, Critical Care and Pain, 2005; 5 (4): 122-26.

6. Linda NG, John M. Libertino. Adrenocortical carcinoma: Diagnosis, evaluation and treatment. The Journal of Urology, 2003 Jan; 169 (1): 5-11.

7. Libe R, Fratticci A, Bertherat J. Adrenocortical cancer: pathophysiology and clinical management. Endocrine-Related Cancer, 2007; 14; 13-28. 


\section{CASE REPORT}

8. Alan P. B. Dackiw, Jeffrey E. Lee, Robert F. Gagel, Douglas B. Evans. Adrenal Cortical Carcinoma. World J. Surg. 2001 July; 25 (7): 914-926.

9. Talwar N, Andley M, Ravi B, Kumar A. Cushing's syndrome in a young woman: A rare presentation of adrenocortical carcinoma. JK Science 2008 Jan-Mar; 10 (1): 31-32.

10. Miller BS, Ammori JB, Gagger PG, Broome JT, Hammer GD, Doherty GM. Laparoscopic resection is inappropriate in patients with known or suspected adrenocortical carcinoma. World J Surg. 2010 Jun; 34 (6): 1380-85.

11. Chiche L, Dousset B, Kieffer E, Chapuis Y. Adrenocortical carcinoma extending into the inferior vena cava: presentation of a 15 - patient series and the review of the literature. Surgery, 2006 Jan; 139 (1): 15-27.

12. Nizamoglu A, Salihoglu Z, Bolayrl M. Effects of epidural - and - general anaesthesia combined versus general anaesthesia during laparoscopic adrenalectomy. Surg Laparosc Endosc Percutan Tech, 2011 Oct; 21 (5): 372-9.

13. ACK Fok, AYS Tan, APY Chong, PPB Yeo. Adrenal cortical carcinoma: A report of two cases and a review of the literature. Sing Med J. 1988; 29: 513-518.

14. Mikhalakis K, Ilias I. Medical management of adrenal disease: A narrative review. Endocrine Regulations, 2009; 43: 127-135.

15. Domi R. Cushing's surgery: Role of anaesthesiologist. Indian Journal of Endocrinology and Metabolism, 2011; 15 (4): 322-328.

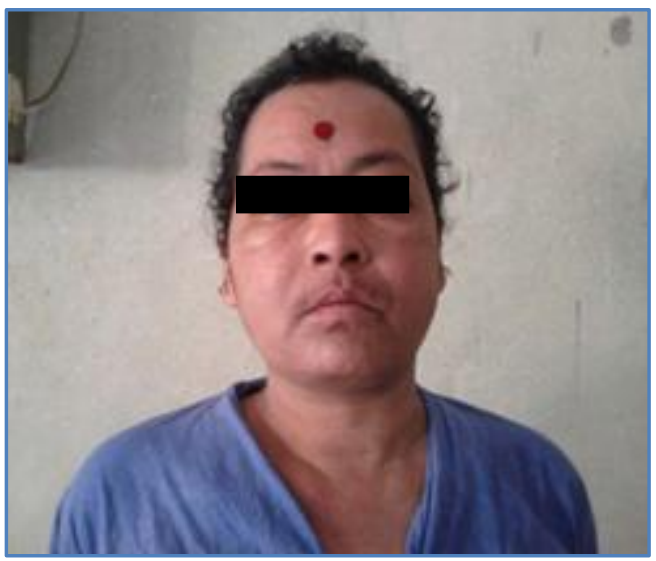

Photo 1: Showing moon face, hirsuitism

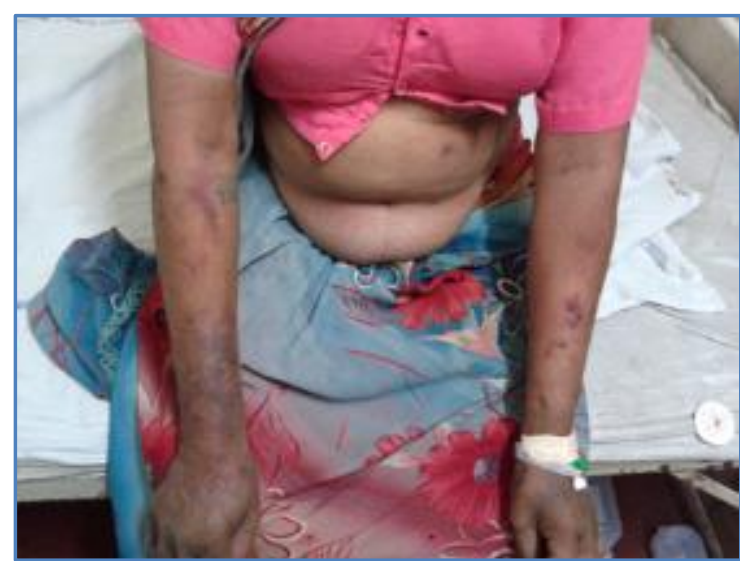

Photo 2: Showing ecchymotic patches 


\section{CASE REPORT}

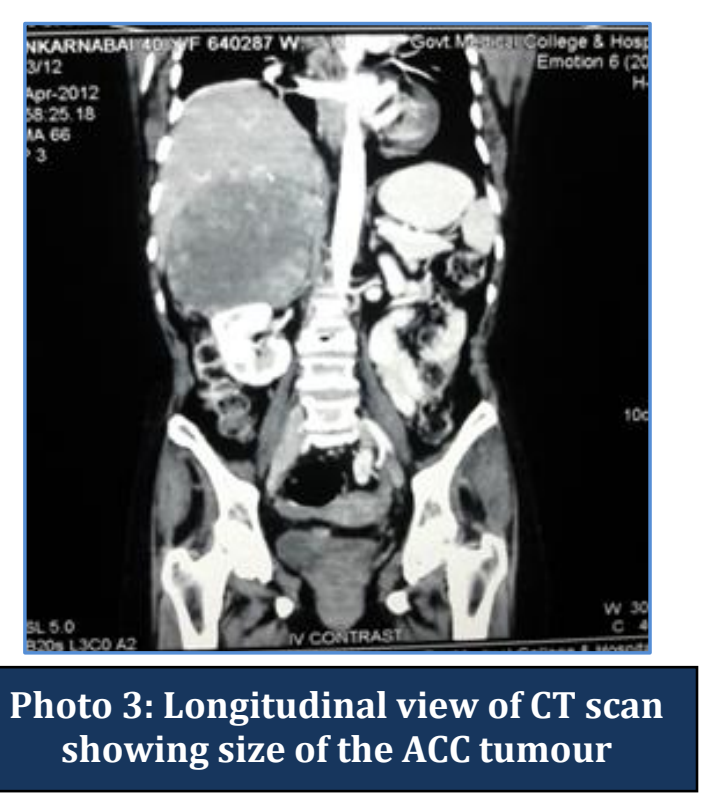

\section{AUTHORS:}

1. Mukund Parchandekar

2. Poornima Sonkamble

3. Sneha Sikchi

4. Kirankumar Nagure

\section{PARTICULARS OF CONTRIBUTORS:}

1. Assistant Professor, Department of Anaesthesiology, Government Medical College, Aurangabad, Maharashtra.

2. Assistant Professor, Department of Anaesthesiology, Government Medical College, Aurangabad, Maharashtra.

3. Junior Resident, Department of Anaesthesiology, Government Medical College, Aurangabad, Maharashtra.

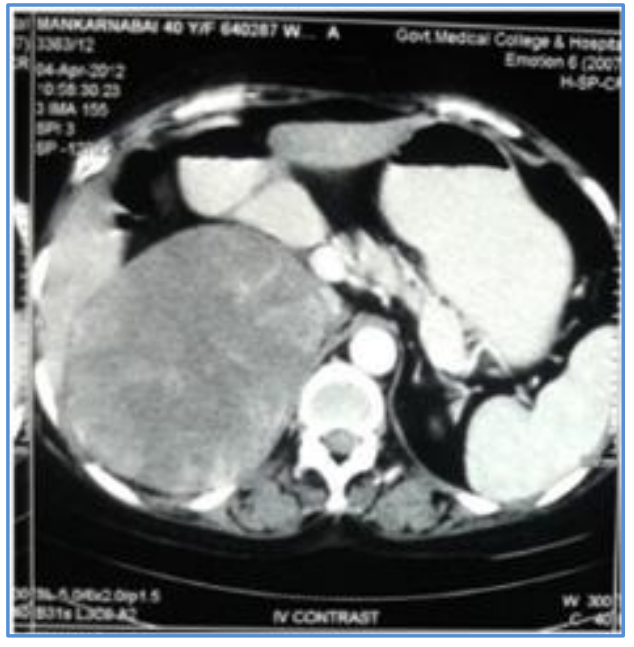

\section{Photo 4: Cross-sectional view of CT scan} showing size of the ACC tumour

4. Junior Resident, Department of Anaesthesiology, Government Medical College, Aurangabad, Maharashtra.

\section{NAME ADDRESS EMAIL ID OF THE CORRESPONDING AUTHOR:}

Dr. Mukund Parchandekar,

House No. 1-12-121,

Saraswati-Kunj,

Shahu Nagar, Nanded-431602,

Maharashtra, India.

Email: drpmukund@yahoo.com

Date of Submission: 10/09/2014.

Date of Peer Review: 11/09/2014.

Date of Acceptance: 18/09/2014.

Date of Publishing: 25/09/2014. 